\title{
FREE DIFLUCAN HERE!
}

World AIDS Day (December 1st) at the end of last year saw the signing of a groundbreaking public-private partnership agreement between Pfizer Pharmaceuticals and the South African Ministry of Health. The Memorandum of Understanding that defines the conditions of Pfizer's 2-year donation of free Diflucan to South Africa (estimated at a market value of R375 million) was the culmination of months of negotiations to ensure that South Africa benefits appropriately from the offer.

Through this process, which has been severely criticised by the Treatment Action Campaign as creating unacceptable delays to making this treatment accessible, the Department of Health has achieved agreement on expanding the indications for using the donated drug to include both cryptococcal meningitis and oesophageal candidiasis. Pfizer also committed to making the offer available to other SADC countries, in compliance with the SADC Health Ministers' stated strategy for taking on international pharmaceutical offers as part of a regional response.

Pfizer has made a significant additional commitment to support the development of knowledge and skills in implementing the Diflucan Partnership Programme through funding professional training that is part of the Department of Health's broader strategy to build the capacity of all healthcare workers managing the epidemic, providing training for guideline-supported best practices.

The agreement has been cited as an important example of what can be achieved through enabling partnerships that add value and scope to the care that is delivered to HIVaffected populations. It is hoped that this will encourage similar initiatives that are able to bring more hope to AIDS sufferers in the region. For South Africa, this is important as the first treatment access programme to result from challenging the pharmaceutical multinationals to make HIV medications more generally available to HIV-affected populations in developing countries.

The implementation of this initiative is being overseen at a top level by a Ministerial Working Group, which has already held a number of strategy meetings to ensure that the intervention is made widely available as soon as possible.

In mid February, the MCC fast-tracked its registration of the donation formulation (which differs from the commercially available capsule in that it is a blue $200 \mathrm{mg}$ tablet), and it is anticipated that institutions should have stock available for prescription before the end of March.
Careful procedures have been put in place to regulate the dispensing of donation stock to ensure that it is used only for the indications allowed and to prevent stock diversion, although the Ministry of Health has confirmed that no patient will be refused access to this treatment, even if they are referred from the private sector.

The Southern Africa Regional Office of IAPAC (The International Association of Physicians in AIDS Care) has been given the responsibility to facilitate the training of health care workers on the best practices relating to using Diflucan and for managing $\mathrm{CM}$ and $\mathrm{OC}$. This training will take place in a phased approach that initially targets the institutions in each province where the drug is to be made available.

IAPAC's 'AIDS Care Faculty', a network of experienced health professionals through which ongoing training activities will take place, is seen as a regional asset that will facilitate the cascade of information flow and professional education relating to HIVIAIDS best practices and lead to a growth in both the numbers and capacity of trained health care workers managing the disease appropriately.

Fact Sheets that summarise these best practices have been published. In addition, modular training materials for nurses, doctors and patients are being developed and will be available from IAPAC.

Clinicians are encouraged to actively participate in training activities where these are offered and to ensure that patients are identified early and referred to participating institutions to make the most of this intervention.

The Diflucan Parnership Programme offers an important opportunity to impact on the care of AIDS patients, but its success will depend on how well the drug is used and how many patients are identified and referred for treatment.

Patients presenting with $\mathrm{CM}$ have a poor longer-term survival prognosis and here are particular challenges to managing AIDS patients with CM and also important opportunities not to be missed in identifying vulnerable households of patients that will benefit from social interventions, such as planning for orphan care.

The Diflucan Partnership Programme is therefore seen as an important catalyst for improving how AIDS patients are treated and cared for.

IAPAC is facilitating a toll-free Diflucan Hotline on the number 08003435821 for any enquiries relating to where the drug is available, how it should be used and how to access training and other resources.

The Diflucan Partnership Programme website (www.dpp.org.za) is an additional source of resources, information and training materials. 